ISSN 0103-9954

\title{
BRANQUEAMENTO ECF E TCF DE CELULOSE DE FIBRAS SECUNDÁRIAS
}

\section{ECF AND TCF BLEACHING OF SECONDARY FIBER PULP}

\author{
Gustavo Ventorim $^{1} \quad$ Jorge L. Colodette ${ }^{2}$ Marcelo M. da Costa ${ }^{3} \quad$ Ana Campos de Brito ${ }^{4}$
}

\section{RESUMO}

Neste estudo foram avaliadas seqüências ECF e TCF para o branqueamento de celulose de fibras secundárias destintadas provenientes de uma mistura de composição conhecida de lixo de escritório (MOW) e produzidas em planta piloto. A polpa foi branqueada a um nível mínimo de alvura de $78 \%$ ISO, sendo que o requerimento de reagentes e as principais propriedades da polpa foram avaliadas. Dentre as sequiência ECF, a mais atrativa foi a DEDD que apresentou o mais baixo custo e ainda eliminou toda a fluorescência e grande parte da coordenada de cor $b^{*}$ da polpa. As seqüências ECF resultaram em polpas de alta viscosidade em relação às convencionais. A seqüência TCF com ozônio mais atrativa foi a $\mathrm{Q}(\mathrm{PO})(\mathrm{ZQ})(\mathrm{PO})$ que se mostrou flexível quanto ao teto de alvura, além de reduzir significativamente a coordenada de cor $b^{*}$ e ligeiramente a fluorescência da polpa. A melhor seqüência TCF sem-ozônio Q(PO)Q(PO) apresentou-se pouco flexível quanto ao teto de alvura e teve pouco efeito na fluorescência e coordenada de cor $b^{*}$ da polpa. As viscosidades finais das polpas, branqueadas pelos processos TCF, foram aceitáveis. Os resultados de rendimento, para os processos avaliados nesse estudo, foram afetados negativamente por estágios alcalinos, como $\mathrm{O}, \mathrm{P}$ e (PO), em alta temperatura.

Palavras-chave: Fibras secundárias, processos de branqueamento (ECF e TCF).

\begin{abstract}
In this study, ECF and TCF bleaching processes were evaluated for the bleaching of a deinked mixed office waste (MOW) pulp sample produced in a pilot plant. The sample was bleached by all processes to a target brightness of $78 \%$ ISO minimum. The results were interpreted on the basis of chemical cost to reach the target brightness, bleaching yield and bleached pulp quality as measured by viscosity, fluorescence and $b^{*}$ color coordinate. Among the ECF sequences, the mosattractive was the DEDD which showed the lowest chemical cost and produced bleached pulp of high quality as measured by viscosity, fluorescence and $b^{*}$ coordinate. The best TCF sequence with ozone was the $\mathrm{Q}(\mathrm{PO})(\mathrm{ZQ})(\mathrm{PO})$ which resulted in very high brightness ceiling. This sequence decreased moderately the pulp $b^{*}$ coordinate and viscosity and slightly its fluorescence. Among the

1. Químico, Pós-Graduado em Ciência Florestal. Centro de Ciências Agrárias, Universidade Federal de Viçosa, CEP: 36570000,Viçosa. (MG).

2. Engenheiro Florestal, PhD., Professor Titular do Departamento de Engenharia Florestal, Centro de Ciências Agrárias, Universidade Federal de Viçosa, CEP: 36570-000, Viçosa. (MG).

3. Engenheiro Florestal, Doutorando em Ciência Florestal, Centro de Ciências Agrárias, Universidade Federal de Viçosa, CEP: 36570-000, Viçosa. (MG).

4. Engenheira Químico, White Martins Gases Industriais S.A., CEP: 25225-170, Rio de Janeiro. (RJ).
\end{abstract}


TCF sequences without ozone the $\mathrm{Q}(\mathrm{PO}) \mathrm{Q}(\mathrm{PO})$ was the most effective but showed poor flexibility with regard to brightness ceiling. This sequence had little effect on pulp viscosity, fluorescence and $\mathrm{b}^{*}$ coordinate. For all three bleaching processes, it was determined that process yield is negatively affected by hot alkaline stages such as $\mathrm{O}, \mathrm{P}$ and (PO).

Key-word: Secondary fibers, bleaching process (conventional, ECF and TCF).

\section{INTRODUÇÃO}

A importância das celulose de fibras secundárias está crescendo cada vez mais no cenário mundial e grandes investimentos em pesquisas estão sendo realizados, objetivando desenvolver tecnologias para o seu aproveitamento. No ano de 1995, a taxa média de reciclagem de papéis foi de $40 \%$ do consumo mundial desses produtos. Os centros que apresentaram as maiores taxas de reciclagem foram a Suécia (53\%), o Japão (52\%), a Europa Ocidental (46\%) e os EUA (45\%), enquanto que o Brasil apresentou uma taxa de reciclagem de 35-37\%. Durante o período de 19901995, o crescimento do consumo anual de celulose de fibras secundárias foi de 6,3\%, contra apenas 2,9\% de fibras virgens. Estimativas prevêem que para o período de 1994-2004, o consumo de papéis reciclados crescerá em torno de $4 \%$ ao ano, enquanto que o consumo de fibras virgens crescerá, em média, apenas $2,7 \%$.

Sob um ponto de vista ambientalista, quando se utilizam as celulose de fibras secundárias se reduz o consumo de madeira. Isso é uma das características mais desejáveis no uso dessas fibras, já que não resulta em abate de florestas (D’ALMEIDA \& CAHEM, 1991). Por outro lado, a reciclagem de fibras contribui para um menor acúmulo de lixo nos grandes centros urbanos e na redução de poluição hídrica e atmosférica, em relação a processos químicos de produção de fibras virgens. Por outro lado, o processo de reciclagem requer menos energia que processos mecânicos de polpação.

$\mathrm{O}$ crescimento da área urbana, aliado à necessidade de preservar-se florestas, tem reduzido as áreas florestáveis, aumentando os custos destinados à compra de terra, especialmente nos países europeus. Esse fato resulta num incremento de preço da madeira utilizada como matéria-prima na produção de fibras virgens.

Usualmente, as celuloses de fibras secundárias são branqueadas a baixas alvuras para atender a usos menos nobres do papel. $\mathrm{O}$ branqueamento, na sua maior parte, é efetuado com reagentes à base de cloro. São muito comuns os processos em uma única etapa com hipoclorito $(\mathrm{H})$ ou em seqüências tais como $\mathrm{HH}$, cloração (C) e hipocloração e cloração, extração (E) e hipocloração $\mathrm{CEH}$, sendo a última mais aplicável para a celulose de fibras secundárias que apresentam maiores teores de lignina (STUS, 1996; NADDEO et al., 1992; SING, 1976). Processos de branqueamento que não envolvem o uso do cloro têm também sido utilizados, incluindo processos somente com peróxido de hidrogênio $(\mathrm{P})$, tais como $\mathrm{P}$ e PP ou peróxido combinado com agentes redutores, tais como hidrosulfito de sódio (Y) e ácido formamidino sulfínico (FAS), em seqüências tais como PY ou PFAS (PATT et al., 1996). Porém, exigências de mercado aliadas a legislações ambientais mais restritivas têm inviabilizado o branqueamento convencional, exigindo tecnologias menos agressivas

Ciência Florestal, v. 9, n. 2, 1999 
ao meio ambiente.

Os requerimentos de qualidade das celulose de fibras secundárias têm crescido acentuadamente. Essas fibras, que no passado eram usadas para fins menos nobres, estão alcançando nichos de mercado mais exigentes, especialmente quanto aos seus níveis de alvura que são, atualmente, ocupados por fibras virgens branqueadas vindas de madeiras de folhosas.

Em razão da grande heterogeneidade desse material, o branqueamento de celulose de fibras secundárias, a elevados níveis de alvura e a custos competitivos, é complexo. Outro fato importante é que o uso dos eficientes compostos à base de cloro não é mais bem-aceito para branquear esse tipo de fibra, sob o ponto de vista ambiental.

O branqueamento é a etapa de maior complexidade na manufatura de papéis de alta qualidade, com base na celulose de fibras secundárias. A composição das celulose de fibras secundárias é determinante, sendo que as do tipo kraft não-branqueadas e as oriundas de processos mecânicos de polpação são as que apresentam as maiores dificuldades de branqueamento. As polpas kraft nãobranqueadas contêm, usualmente, elevados teores de lignina modificada, pois são provenientes de caixas de papelão, e as de pasta mecânicas contêm toda a lignina não-modificada, originalmente, presente na madeira. A química de branqueamento desses dois tipos de lignina diferem desses, grandemente. Algumas celuloses de fibras secundárias, contêm ainda combinações de corantes e ligninas que apresentam pequena reatividade frente aos reagentes de branqueamento comercias e também possuem os pigmentos de carbono preto que não reagem. Por outro lado, resinas, usadas para promover a cura de certos tipos de tintas e colas usadas na colagem do papel, podem interagir com os reagentes de branqueamento (DALTON, 1991; NADDEO et al., 1994a, 1994b, 1993a, 1993b, 1991).

A escolha da melhor tecnologia para o branqueamento de uma determinada amostra de fibra secundária depende, largamente, da composição de fibras do material de origem. Assim sendo, o objetivo desse estudo foi o de branquear a altos níveis de alvura, 78-82\% ISO, uma amostra de celulose de fibras secundárias destintadas obtida de uma mistura de lixo de escritório. Para alcançarse tal objetivo, foram avaliados processos de branqueamento isentos de cloro elementar (ECF) e isentos de compostos à base de cloro (TCF), utilizando-se reagentes tais como dióxido de cloro, oxigênio, ozônio, peróxido de hidrogênio e hidrosulfito de sódio.

\section{MATERIAL E MÉTODOS}

Foi utilizado, nesse estudo, uma amostra de celulose de fibras secundárias destintadas em planta piloto, sendo ela representativa da mistura de lixo de escritório, comumente denominada como MOW (mixed office waste). As principais características iniciais da amostra eram alvura de 55,1\% ISO; número kappa de 14,4; fluorescência de 1,92\% ISO; viscosidade de 11,9 mPa.s e coordenada de cor $b^{*}$ de 11,60. Os tipos de papéis que compunham a amostra estão apresentados na Figura 1. Na Tabela 1, é mostrada a composição das diversas fibras que constituiam a amostra em questão. 


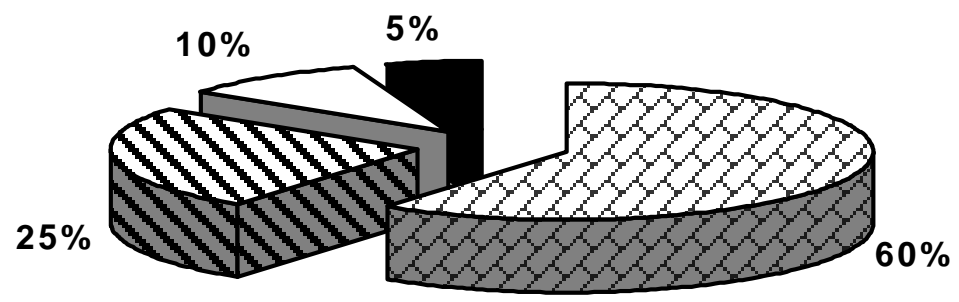

$\square$ Papel branco com impressão a laser

$\mathbf{\Delta}$ Papel com impressão colorida

Papel velho de pasta mecânica

Papel kraft não branqueado

Figura 1: Os vários tipos de papéis presentes na amostra.

As várias etapas de branqueamento foram efetuadas com amostras de tamanho variado e em diferentes reatores. A extração oxidativa com peróxido $\left(E_{P}\right)$, a deslignificação com oxigênio $(O)$, e o branqueamento com peróxido pressurizado (PO) foram efetuados em reatores de aço-inox, com capacidade para injeção de gases e pressurização. Os estágios de quelação (Q), de dioxidação (D), de hidrosulfitação (Y), de extração (E) e de peroxidação convencional (P) foram efetuados em sacos de polietileno. $\mathrm{O}$ branqueamento com ozônio foi efetuado em reator de vidro, pela passagem de um fluxo de gás de concentração conhecida de ozônio em um leito de polpa previamente afofada, sob constante mistura. O ozônio residual foi coletado em solução de KI 5\% e titulado por iodometria. O consumo de ozônio, pela polpa, foi determinado pela diferença entre ozônio aplicado e ozônio residual. A lavagem da polpa, após cada etapa de branqueamento, foi efetuada sempre com excesso de água, exceto nos casos em que pela natureza dos experimentos, a lavagem foi omitida. De cada etapa de branqueamento, foi determinado o rendimento e extraídas amostras de licor para análise de $\mathrm{pH}$ e residuais.

As seqüências de branqueamento avaliadas neste estudo foram:

$\mathrm{ECF}=\mathrm{DEDD}, \mathrm{DE}_{\mathrm{P}} \mathrm{DD}, \mathrm{DP}$ e ODP

$\mathrm{Z}-\mathrm{TCF}=\mathrm{Q}(\mathrm{PO})(\mathrm{ZQ})(\mathrm{PO}), \mathrm{Q}(\mathrm{PO}) \mathrm{Z}(\mathrm{PO}), \mathrm{O}(\mathrm{ZQ})(\mathrm{PO}),(\mathrm{ZQ})(\mathrm{PO}),(\mathrm{ZQ})(\mathrm{PO}) \mathrm{ZY}$ e Z(PO)ZY $)$

TCF: Q(PO)Q(PO) e Q(PO)Q(PO)Y.

As condições gerais de cada estágio de branqueamento estão apresentadas na Tabela 2.

TABELA 1: Tipos de fibras presentes na amostra.

\begin{tabular}{l|c}
\hline \multicolumn{1}{c|}{ Tipo de fibra } & Composição da amostra, \% \\
\hline Kraft branqueada de fibra longa & 31 \\
Kraft branqueada de fibra curta & 39 \\
Kraft não-branqueada de fibra longa & 4 \\
Sulfito branqueada de fibra curta & 17 \\
Pasta mecânica de fibra longa & 8 \\
Pasta quimiomecânica de fibra longa & 1 \\
\hline
\end{tabular}

Ciência Florestal, v. 9, n. 2, 1999 
TABELA 2: Condições gerais do branqueamento.

\begin{tabular}{|c|c|c|c|c|c|c|c|c|c|c|c|}
\hline \multirow{2}{*}{$\begin{array}{c}\text { Condições } \\
\text { do branqueamento }\end{array}$} & \multicolumn{11}{|c|}{ Estágios } \\
\hline & $\mathrm{O}$ & $\mathrm{D}_{0}$ & $\mathrm{D}$ & $E$ & $\mathrm{E}_{\mathrm{P}}$ & $\mathrm{P}$ & $(\mathrm{PO})$ & $(\mathrm{PO})$ & $\mathrm{Q}$ & $\mathrm{Z}$ & $\mathrm{Y}$ \\
\hline Consistência, \% & 10 & 10 & 10 & 10 & 10 & 10 & 10 & 10 & 10 & 45 & 10 \\
\hline Temperatura, ${ }^{\circ} \mathrm{C}$ & 100 & 60 & 70 & 70 & 70 & 70 & 100 & 110 & 60 & - & 60 \\
\hline Tempo, min & 60 & 30 & 180 & 60 & 60 & 60 & 60 & 120 & 30 & - & 30 \\
\hline Pressão, kPa & 600 & - & - & - & - & - & - & - & - & - & - \\
\hline PH,final & 12 & 3.7 & 4.5 & 12 & 12 & 10 & 10.2 & 10.5 & 5.5 & 2.5 & 5 \\
\hline $\mathrm{ClO}_{2}, \mathrm{~kg} / \mathrm{t}$ como $\mathrm{Cl}_{2}$ & - & 34.6 & var & - & - & - & - & - & - & - & - \\
\hline $\mathrm{NaOH}, \mathrm{kg} / \mathrm{t}$ & 20 & - & - & 9 & 10 & var & var & var & - & - & - \\
\hline $\mathrm{H}_{2} \mathrm{O}_{2}, \mathrm{~kg} / \mathrm{t}$ & - & - & - & - & 5 & 20 & var & var & - & - & - \\
\hline $\mathrm{O}_{2}, \mathrm{~kg} / \mathrm{t}$ & 20 & - & - & - & - & - & - & - & - & - & - \\
\hline $\mathrm{O}_{3}, \mathrm{~kg} / \mathrm{t}$ & - & - & - & - & - & - & - & - & - & var & - \\
\hline $\mathrm{MgSO}_{4}, 7 \mathrm{H}_{2} \mathrm{O}, \mathrm{kg} / \mathrm{t}$ & 2 & - & - & - & - & 2 & 2 & 2 & - & - & - \\
\hline $\mathrm{Na}_{2} \mathrm{~S}_{2} \mathrm{O}_{4}, \mathrm{~kg} / \mathrm{t}$ & - & - & - & - & - & - & - & - & - & - & 5 \\
\hline $\mathrm{Na}_{2} \mathrm{SiO}_{3}, \mathrm{~kg} / \mathrm{t}$ & - & - & - & - & - & 30 & 15 & 15 & - & - & - \\
\hline EDTA, $\mathrm{kg} / \mathrm{t}$ & - & - & - & - & - & - & - & - & $2 / 1$ & - & - \\
\hline
\end{tabular}

Sendo: Var = variável 3.

Os principais parâmetros analisados e seus procedimentos analíticos são mostrados na Tabela

TABELA: 3 Análises realizadas e seus respectivos procedimentos.

\begin{tabular}{lc}
\hline \multicolumn{1}{c}{ Principais parâmetros analisados } & Procedimentos Analíticos \\
\hline Número Kappa & TAPPI T 236 om-85 \\
Viscosidade (CED) & TAPPI T 230 om-85 \\
Formação de folhas para medição de alvura & CPPA C.5 \\
Alvura, com e sem o filtro de luz U.V. & TAPPI T 452 om-86 \\
Fluorescência & TAPPI T 452 om-86 \\
Análise de fibra do papel e papelão & TAPPI T 401 om-88 \\
Análise de cinza & TAPPI T 211 cm-86 \\
Coordenadas de cor L*a*b* & TAPPI T $524 \mathrm{om}-86$ \\
Metais (espectrofotometria de absorção atômica) & TAPPI T 266 om-88 \\
Rendimento, $\%$ & Gravimetria \\
\hline
\end{tabular}

O custo total do branqueamento foi calculado com base nas dosagens (kg/t a.s.) e nos preços (US\$/kg) dos reagentes utilizados nos vários estágios de branqueamento. Os preços dos reagentes foram obtidos no mercado internacional. O custo total foi determinado pelo somatório dos custos de reagentes de cada estágio individual, levando-se em consideração o rendimento de cada etapa. Os números apresentados como subscrito nas simbologias dos vários processos indicam as dosagens de reagentes utilizadas nos vários estágios de branqueamento, em kg/t.a.s. de polpa não- branqueada. 


\section{RESULTADOS E DISCUSSÃO}

O estudo de branqueabilidade da amostra de celulose de fibras secundárias incluiu processos ECF (isentos de cloro molecular), Z-TCF (isentos de compostos à base de cloro, com ozônio) e TCF (isentos de compostos à base de cloro, sem-ozônio). Os resultados dos branqueamentos efetuados com essas três tecnologias são discutidos, separadamente, nas secções seguintes. Os números apresentados, como subscrito nas simbologias dos vários processos, indicam as dosagens de reagentes utilizadas nos vários estágios de branqueamento, em kg/t.a.s. de polpa não-branqueada. Os resultados foram interpretados em termos de alvura, viscosidade, fluorescência e coordenada de cor b* da polpa branqueada, e com base no rendimento e no custo de reagentes dos vários processos de branqueamento.

\section{Branqueamento ECF}

O branqueamento por processos ECF apresenta a vantagem de gerar um efluente menos nocivo ao meio ambiente, em relação a processos convencionais. $\mathrm{O}$ principal reagente utilizado no branqueamento ECF, o dióxido de cloro, gera cinco vezes menos compostos organoclorados durante o branqueamento, em relação ao cloro elementar (AXEGARD, 1989). Na Tabela 4, são apresentados resultados para os vários processos de branqueamento ECF avaliados.

TABELA 4: Resultados do branqueamento ECF.

\begin{tabular}{l|c|c|c|c}
\hline \multirow{2}{*}{ Resultados } & \multicolumn{4}{|c}{ Processos de Branqueamento } \\
\cline { 2 - 5 } & $\mathrm{D}_{34,6} \mathrm{ED}_{20} \mathrm{D}_{10}$ & $\mathrm{D}_{34,6} \mathrm{E}_{\mathrm{P}} \mathrm{D}_{20} \mathrm{D}_{5}$ & $\mathrm{D}_{34,6} \mathrm{P}_{20}$ & $\mathrm{O}_{20} \mathrm{D}_{34,6} \mathrm{P}_{20}$ \\
\hline Alvura, \% ISO & 77,9 & 79,9 & 76,6 & 82,4 \\
Número kappa & 2,0 & 2,1 & - & 4,4 \\
Fluorescência, \% ISO & $-0,08$ & $-0,54$ & 0,56 & 0,55 \\
Viscosidade, mPa.s & 10,2 & 10,0 & 9,5 & 9,1 \\
$\Delta$ Alvura, \% ISO & $+22,8$ & $+24,8$ & $+21,5$ & $+27,3$ \\
$\Delta$ Número kappa, \% & $-86,1$ & $-85,4$ & - & $-69,4$ \\
$\Delta$ Fluorescência, \% ISO & $-2,0$ & $-2,46$ & $-1,32$ & $-1,33$ \\
$\Delta$ Viscosidade, \% & $-14,3$ & $-16,0$ & $-20,2$ & $-23,5$ \\
Rendimento total, \% & 93,4 & 90,1 & 96,5 & 88,9 \\
Custo total, US\$/t.a.s. & 31,31 & 36,00 & 46,19 & 60,43 \\
Coordenada de cor b* & 4,67 & 4,63 & 5,19 & 4,73 \\
\hline
\end{tabular}

Exceto pela sequiência DP, todas as outras alcançaram a alvura objetivo de 78-82\% ISO, com o uso de níveis razoáveis de reagentes químicos. As seqüências DEDD e DEpDD eliminaram toda a fluorescência da polpa, mas as seqüências DP e ODP deixaram ainda cerca de $28 \%$ da fluorescência original. Todas as seqüências decresceram o grau de coloração amarelo da polpa, medido pela coordenada de cor b*. De acordo com PARTHASARATHY (1997) o dióxido de cloro é o reagente de branqueamento mais efetivo na remoção de cor de celulose de fibras secundárias. $\mathrm{O}$ grau de eficiência de remoção da coordenada de cor b* variou pouco entre os vários processos, sendo em média cerca de $60 \%$. 
O branqueamento ECF da polpa, resultou em número kappa de 2 unidades para as seqüências DEDD e $\mathrm{DE}_{\mathrm{P}} \mathrm{DD}$ e de 4,4 unidades para a sequiência ODP. Isso foi por causa do menor número de estágios da sequiência e também da menor eficiência de deslignificação do peróxido de hidrogênio comparado ao dióxido de cloro. Pouca variação foi observada entre as várias seqüências ECF no que diz respeito à viscosidade final da polpa branqueada.

Dentre as sequiências que alcançaram a alvura objetivo, a que propiciou o maior rendimento, foi a que utilizou somente dióxido de cloro no branqueamento (DEDD), ratificando a grande seletividade do dióxido de cloro no branqueamento de polpa. O menor rendimento foi registrado para a sequiência, contendo uma etapa de oxigênio. As condições fortemente alcalinas, reinantes no branqueamento com oxigênio, promove a solubilização de frações significativas da polpa, particularmente, aquelas oriundas de aditivos utilizados no processo de fabricação dos papéis que originaram a celulose de fibras secundárias. $\mathrm{O}$ menor custo de branqueamento foi também observado para a seqüência realizada somente com dióxido de cloro; isso ocorre em razão da maior eficiência e menor preço do dióxido de cloro em relação ao peróxido de hidrogênio.

Em resumo, pode-se afirmar que dentre as sequiências ECF avaliadas, a mais atrativa para branquear essa amostra, à alvura objetivo de 78-82\% ISO, foi a DEDD. Essa seqüência resultou no menor custo de branqueamento, no maior rendimento e na polpa branqueada de melhor qualidade. Outro fato interessante, a ser observado na Tabela 4, é o potencial benefício oferecido pela etapa de deslignificação com oxigênio. Comparando-se as seqüências DP e ODP, para dosagens similares de dióxido e de peróxido de hidrogênio, verifica-se que a etapa adicional de oxigênio resultou num ganho de alvura da ordem de 6 pontos. Isso se deve, provavelmente, à remoção de contaminantes da celulose de fibras secundárias pelas condições alcalinas utilizadas no estágio de deslignificação com oxigênio (JENNINGS, 1996 e MAKHAM, 1988), como mostrado na Figura 2.

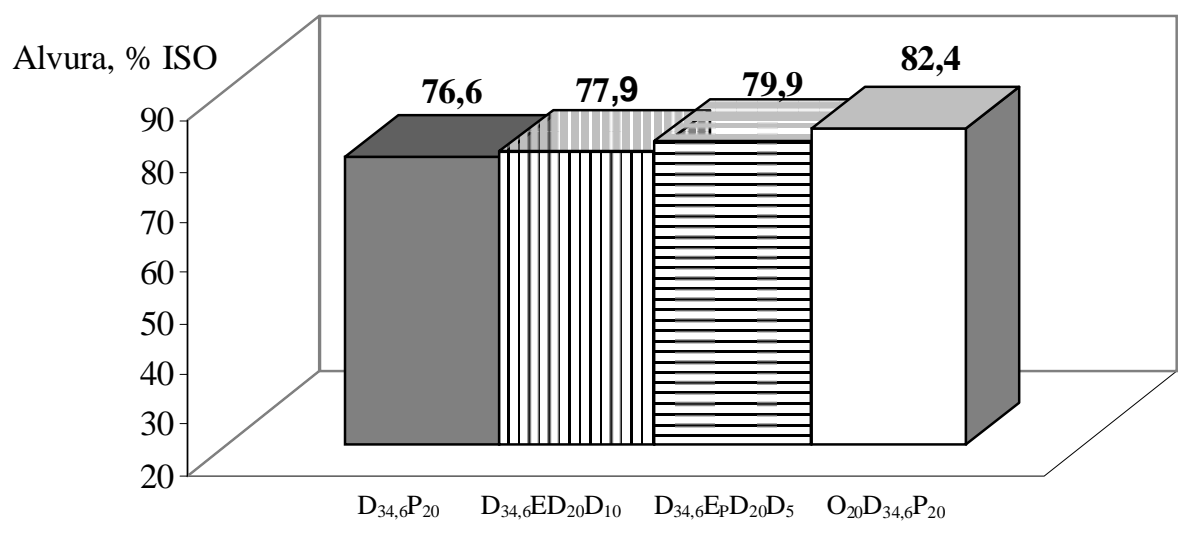

FIGURA 2: Efeito da etapa de deslignificação com oxigênio na alvura da polpa.

\section{Branqueamento TCF com ozônio (Z-TCF)}

As várias seqüências de branqueamento Z-TCF estudadas são apresentadas na Tabela 5. No branqueamento Z-TCF, objetivou-se alcançar a alvura desejada e, concomitantemente, remover o 
máximo de lignina residual da polpa. Por isso, foi utilizado ozônio no processo, reconhecidamente, como bom agente deslignificante.

Analisando-se a Tabela 5, verifica-se que a alvura objetivo de 78-82\% ISO foi alcançada com todas as sequiências de branqueamento. Entretanto, exceto pelos três últimos listados na Tabela 5, todos os processos de branqueamento resultaram em aumento da fluorescência da polpa que era, originalmente, de 1,92\% ISO. O aumento de fluorescência durante o branqueamento é explicado pelo aumento da fluorescência de certos pigmentos existentes nas celulose de fibras secundárias, causado pela ação do peróxido. Embora o ozônio tenha efeito positivo na remoção de fluorescência, em muitos casos o seu efeito é mais do que contrabalançado pela ação negativa do peróxido. No caso das três últimas seqüências, valores mais baixos de fluorescência foram observados, em virtude da presença de duas etapas de ozônio nessas sequiências, além de que o último estágio de hidrosulfito de sódio (Y) pode, em alguns casos, também destruir certos pigmentos fluorescentes.

TABELA 5: Resultados do branqueamento Z-TCF.

\begin{tabular}{|c|c|c|c|c|}
\hline \multirow[t]{2}{*}{ Resultados } & \multicolumn{4}{|c|}{ Processo de Branqueamento } \\
\hline & $\begin{array}{c}\mathrm{Q}_{2}(\mathrm{PO})_{10}\left(\mathrm{Z}_{5} \mathrm{Q}_{1}\right) \\
(\mathrm{PO})_{5}\end{array}$ & $\begin{array}{c}\mathrm{Q}_{2}(\mathrm{PO})_{10} \mathrm{Z}_{15} \\
(\mathrm{PO})_{5}\end{array}$ & $\begin{array}{c}\mathrm{O}_{20}\left(\mathrm{Z}_{10} \mathrm{Q}_{2}\right) \\
(\mathrm{PO})_{20}\end{array}$ & $\left(\mathrm{Z}_{10} \mathrm{Q}_{2}\right)(\mathrm{PO})_{20}$ \\
\hline Alvura, \% ISO & 80,4 & 80,4 & 83,9 & 80,5 \\
\hline Número kappa & 5,6 & 3,4 & 4,6 & 5,0 \\
\hline Fluorescência, \% ISO & 3,3 & 1,96 & 2,63 & 2,52 \\
\hline Viscosidade, $\mathrm{mPa} . \mathrm{s}$ & 9,5 & 8,1 & 8,2 & 8,5 \\
\hline$\Delta$ Alvura, $\%$ ISO & $+25,3$ & $+25,3$ & $+28,8$ & $+25,4$ \\
\hline$\Delta$ Número kappa,$\%$ & $-61,1$ & $-76,4$ & $-68,1$ & $-65,3$ \\
\hline$\Delta$ Fluorescência, \%ISO & $+1,38$ & $+0,04$ & $+0,71$ & $+0,6$ \\
\hline$\Delta$ Viscosidade, $\%$ & $-20,2$ & $-31,9$ & $-31,6$ & $-28,6$ \\
\hline Rendimento total, $\%$ & 93,9 & 93,5 & 88,8 & 93,9 \\
\hline Custo total, US\$/t & 56,29 & 65,78 & 70,49 & 56,25 \\
\hline Coordenada de cor $b^{*}$ & 5,16 & 5,67 & 4,12 & 5,14 \\
\hline \multirow[t]{2}{*}{ Resultados } & \multicolumn{4}{|c|}{ Processo de Branqueamento } \\
\hline & $\left(\mathrm{Z}_{10} \mathrm{Q}_{2}\right)(\mathrm{PO})_{20} \mathrm{Z}_{5} \mathrm{Y}_{5}$ & $\mathrm{Z}_{10}(\mathrm{PO})$ & ${ }_{5} \mathrm{Y}_{5}$ & $\mathrm{Z}_{5}(\mathrm{PO})_{20} \mathrm{Z}_{10} \mathrm{Y}_{5}$ \\
\hline Alvura, \% ISO & 82,3 & 80,6 & & 77,9 \\
\hline Número kappa & 3,0 & $3,($ & & 2,9 \\
\hline Fluorescência, \% ISO & 1,51 & 0, & & 1,19 \\
\hline Viscosidade, mPa.s & 6,7 & 6,4 & & 6,3 \\
\hline$\Delta$ Alvura, \% ISO & $+27,2$ & $+25,5$ & & $+22,8$ \\
\hline$\Delta$ Número kappa , \% & $-79,2$ & -79, & & $-79,9$ \\
\hline$\Delta$ Fluorescência, \%ISO & $-0,41$ & -0, & & $-0,73$ \\
\hline$\Delta$ Viscosidade, $\%$ & $-43,7$ & $-46,2$ & & $-47,1$ \\
\hline Rendimento total, $\%$ & 93,9 & 96,2 & & 97,0 \\
\hline Custo total, US\$/t & 71,96 & 67,2 & & 66,76 \\
\hline Coordenada de cor $b^{*}$ & 4,49 & 5,5 & & 5,59 \\
\hline
\end{tabular}

Ciência Florestal, v. 9, n. 2, 1999 
A coordenada de cor $b^{*}$ foi decrescida em mais de $50 \%$ por todas as sequiencias de branqueamento. O número kappa da polpa branqueada pelos vários processos foi reduzido em 60 $80 \%$, sendo as sequiências com duas etapas de ozonização, as mais eficientes. Os valores residuais de número kappa foram, em todos os casos, ainda substancialmente altos $(>2,8)$, podendo prejudicar certas aplicações da polpa branqueada. As viscosidades finais das polpas foram, substancialmente, reduzidas em todos os processos de branqueamento, particularmente naqueles em que foram usados dois estágios de branqueamento com ozônio, resultando em quedas de viscosidade de até 47\%. É fato reconhecido e documentado a queda de viscosidade causada pelo ozônio (COLODETTE et al., 1996). O processo de branqueamento menos agressivo à viscosidade foi o $Q(P O)(Z Q)(P O)$.

$\mathrm{O}$ rendimento do branqueamento foi muito influenciado pela presença de estágios alcalinos (como na deslignificação com oxigênio ou na extração alcalina a quente e também no estágio de peróxido) realizados a alta temperatura na seqüência de branqueamento. Os rendimentos médios foram obtidos com as seqüências contendo dois estágios de peróxido pressurizado, e os mais altos naquelas seqüências contendo apenas um estágio de peróxido pressurizado. Isso ocorre por cauda da alta eficiência de etapas alcalinas à quente, na remoção de impurezas da polpa, especialmente de aditivos. O custo total de reagentes para o branqueamento Z-TCF dessa amostra, pelos vários processos, foi em geral elevado, sendo os menores valores obtidos com as seqüências $\mathrm{Q}(\mathrm{PO})(\mathrm{ZQ})(\mathrm{PO})$ e (ZQ)(PO) e os maiores com as seqüências contendo duas etapas de ozônio, além de uma etapa de redução com ditionito ou com oxigênio.

A obtenção de celulose de fibras secundárias de alta alvura é muito desejável para aquelas aplicações em que se deseja substituir, total ou parcialmente, as fibras virgens. O controle da alvura final desejada pode ser conseguido, simplesmente, pelo ajuste da dosagem de peróxido no último estágio do branqueamento. Essa tendência é ilustrada na Figura 3 na qual é mostrado o efeito do aumento da dosagem de peróxido no último estágio (PO) da sequiência $\mathrm{Q}(\mathrm{PO})(\mathrm{ZQ})(\mathrm{PO})$. Uma alta flexibilidade do ponto de vista de teto de alvura é particularmente interessante no branqueamento de celulose de fibras secundárias, tendo em vista a grande variação da alvura inicial e da branqueabilidade dessas fibras.

Alvura, \% ISO

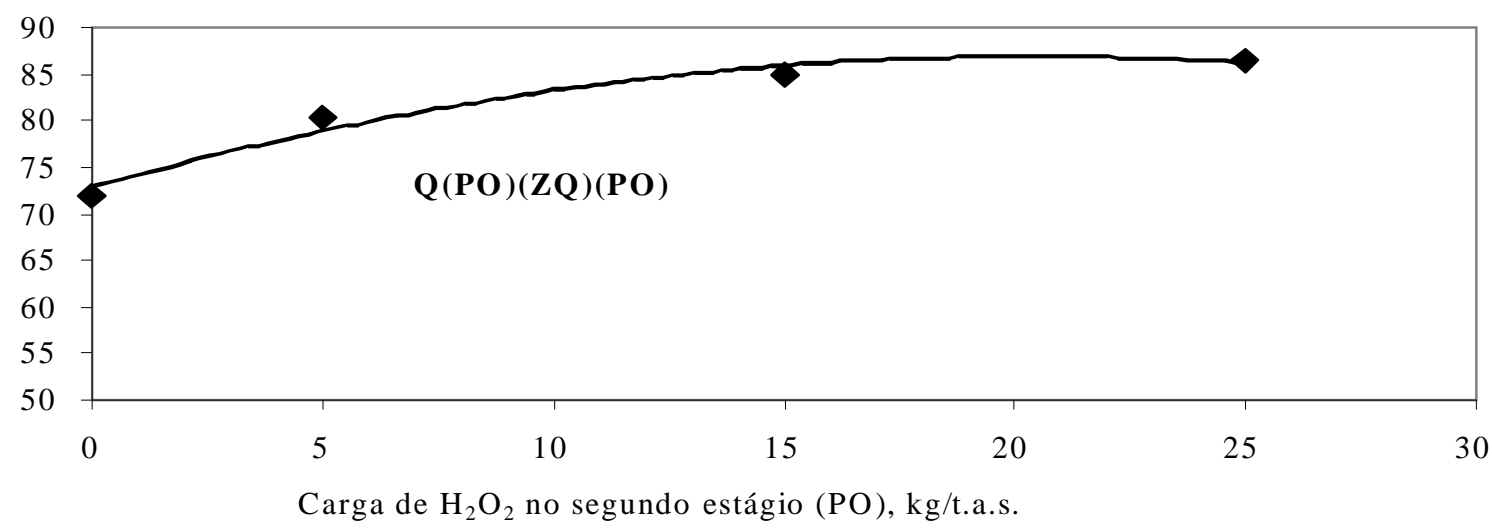

FIGURA 3: Efeito da carga de peróxido de hidrogênio aplicado no segundo estágio (PO) na alvura da polpa branqueada pela sequiência $\mathrm{Q}(\mathrm{PO})(\mathrm{ZQ})(\mathrm{PO})$.

Uma análise geral dos resultados sugere que a sequiência $\mathrm{Q}(\mathrm{PO})(\mathrm{ZQ})(\mathrm{PO})$ é a mais atrativa

Ciência Florestal, v. 9, n. 2, 1999 
para papéis que não requerem eliminação de fluorescência da polpa. Essa seqüência apresentou bom rendimento e baixo custo de reagentes, resultando ainda numa polpa branqueada de excelente qualidade, exceto pela fluorescência. Para papéis que requerem a remoção de fluorescência, a sequiência mais atrativa é a Z(PO)ZY.

\section{Branqueamento TCF sem-ozônio}

No branqueamento TCF sem-ozônio, teve-se como objetivo alcançar a alvura desejada, sem remoção ou com remoção apenas parcial da lignina residual da polpa. Os resultados médios desse estudo estão apresentados na Tabela 6 e nas Figura 4 e Figura 5.

TABELA 6: Resultados do branqueamento TCF.

\begin{tabular}{l|c|c|c|c|c}
\hline \multirow{2}{*}{ Resultados } & \multicolumn{5}{c}{ Processo de Branqueamento } \\
\cline { 2 - 6 } & $\begin{array}{c}\mathrm{Q}_{2}(\mathrm{PO})_{15} \mathrm{Q}_{1} \\
(\mathrm{PO})_{5} \mathrm{Y}_{5}\end{array}$ & $\begin{array}{c}\mathrm{Q}_{2}(\mathrm{PO})_{15} \mathrm{Q}_{1} \\
(\mathrm{PO})_{10}\end{array}$ & $\begin{array}{c}\mathrm{Q}_{2}(\mathrm{PO})_{15} \mathrm{Q}_{1} \\
(\mathrm{PO})_{10} \mathrm{Y}_{5}\end{array}$ & $\begin{array}{c}\mathrm{Q}_{2}(\mathrm{PO})_{15} \mathrm{Q}_{1} \\
(\mathrm{PO})_{15}\end{array}$ & $\begin{array}{c}\mathrm{Q}_{2}(\mathrm{PO})_{15} \mathrm{Q}_{1} \\
(\mathrm{PO})_{15} \mathrm{Y}_{5}\end{array}$ \\
\hline Alvura, \% ISSO & 78,4 & 79,3 & 81,6 & 81,3 & 82,9 \\
Número kappa & 10,5 & 9,8 & 9,9 & 8,5 & 8,5 \\
Fluorescência, \% ISSO & 2,7 & 4,0 & 3,3 & 4,4 & 3,9 \\
Viscosidade, mPa.s & 10,4 & 10,2 & 10,1 & 10,1 & 9,9 \\
$\Delta$ Alvura, \% ISSO & $+23,3$ & $+24,2$ & $+26,5$ & $+26,3$ & $+27,8$ \\
$\Delta$ Número kappa, \% & $-27,1$ & $-31,9$ & $-31,2$ & $-41,0$ & $-41,0$ \\
$\Delta$ Fluorescência, \% ISSO & $+0,78$ & $+2,08$ & $+1,38$ & $+2,48$ & $+1,98$ \\
$\Delta$ Viscosidade, \% & $-12,6$ & $-14,3$ & $-15,1$ & $-15,1$ & $-16,8$ \\
Rendimento total, \% & 94,1 & 93,6 & 93,6 & 93,6 & 93,6 \\
Custo total, US $\$$ t.a.s. & 52,57 & 54,72 & 59,03 & 61,24 & 65,31 \\
Coordenada de cor b* & 6,05 & 4,17 & 4,38 & 3,22 & 3,27 \\
\hline
\end{tabular}

Alvura, \% ISO

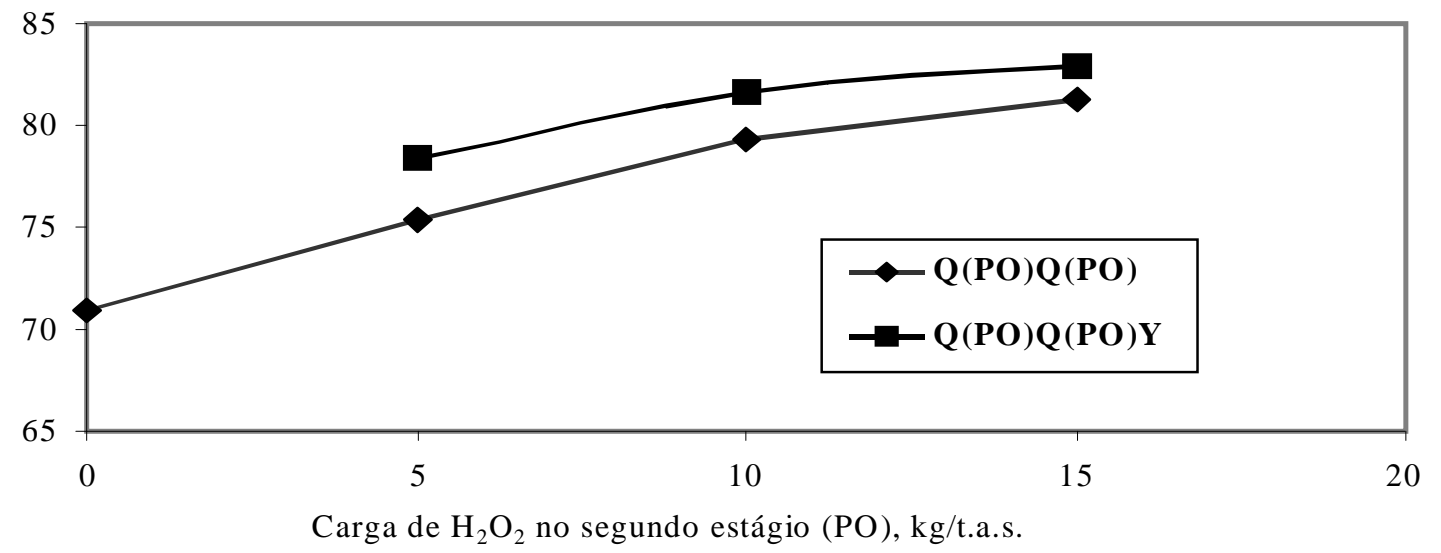

FIGURA 4: Efeito da carga de peróxido de hidrogênio aplicado no segundo estágio (PO) na alvura da polpa branqueada pelas seqüências $\mathrm{Q}(\mathrm{PO}) \mathrm{Q}(\mathrm{PO})$ e $\mathrm{Q}(\mathrm{PO}) \mathrm{Q}(\mathrm{PO}) \mathrm{Y}$. 
Os resultados apresentados na Tabela 6 indicam que a alvura objetivo de 78-82\% ISO foi alcançada pelas sequiências TCF avaliadas. A obtenção de níveis de alvura superiores ao teto estabelecido são possíveis, pelo simples aumento da dosagem de peróxido de hidrogênio na última etapa de peróxido pressurizado. Isso é mostrado nas curvas apresentadas na Figura 4.

A implantação de um estágio adicional de redução (Y), nas seqüências contendo peróxido, resultou em pequenos ganhos de alvura da ordem de 1-2\% ISO. Aparentemente, muitas das estruturas que são descoloradas pelo peróxido, são também sítios de reação para o hidrosulfito e, por isso, os efeitos de branqueamento com peróxido e com hidrosulfito não são aditivos. Por outro lado, ambas as sequiências avaliadas resultaram em aumento da fluorescência da polpa, especialmente nos processos em que dosagens mais altas de peróxido foram utilizadas (Figura 6). A presença de um estágio redutor (Y), na sequiência, decresceu, ligeiramente, a fluorescência da polpa, ratificando o efeito positivo desse reagente na remoção de fluorescência.

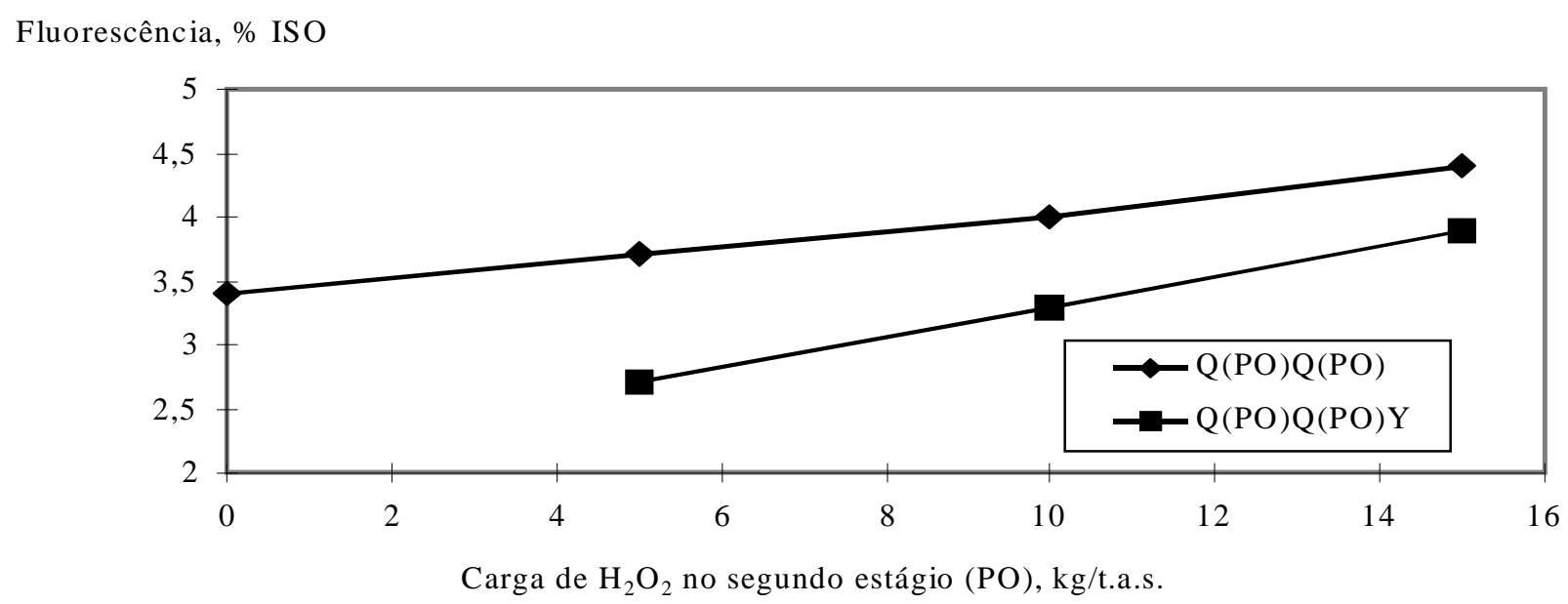

FIGURA 5: Efeito da carga de peróxido de hidrogênio aplicado no segundo estágio (PO) na fluorescência da polpa branqueada pelas seqüências $\mathrm{Q}(\mathrm{PO}) \mathrm{Q}(\mathrm{PO})$ e $\mathrm{Q}(\mathrm{PO}) \mathrm{Q}(\mathrm{PO}) \mathrm{Y}$.

O branqueamento TCF resultou em substancial decréscimo da coordenada de cor $b^{*}$, alcançando reduções de até $72 \%$. A coordenada de cor $b^{*}$ foi reduzida em maior intensidade nas sequiências que utilizaram maiores dosagens de peróxido. O efeito de uma etapa de redução com ditionito na coordenada de cor $b^{*}$ é insignificante. O número kappa da polpa decresceu de $27-41 \%$ durante o branqueamento TCF, mas o objetivo desses processos não era o de remover a lignina da polpa e sim descolorá-la.

Os processos de branqueamento TCF tiveram pouco efeito na viscosidade da polpa, sendo similares as viscosidade finais das polpas branqueadas pelas várias seqüências. $\mathrm{O}$ efeito do peróxido na viscosidade não foi significativo em razão da presença de duas etapas de quelação nas várias sequiências. Com a remoção sistemática de metais, previamente às etapas de peroxidação, o efeito adverso de radicais livres no processo foi minimizado. É bem-conhecido e documentado o efeito negativo dos metais de transição na estabilidade do peróxido de hidrogênio (COLODETTE, 1986). Em geral, todas as seqüências avaliadas resultaram numa queda de rendimento da ordem de $6 \%$, não 
havendo variação significativa entre as seqüências avaliadas. Essa perda de rendimento é atribuível à remoção de materiais solúveis em álcali a quente, principalmente de aditivos existentes nas celulose de fibras secundárias. $\mathrm{O}$ custo do branqueamento para as várias seqüências variou entre 50 e 63 dólares por tonelada de polpa branqueada.

Considerando-se que a adição de uma etapa redutiva no final do branqueamento teve pouco efeito no processo como um todo, não se recomenda o uso do hidrosulfito (Y) para o branqueamento da polpa em questão. Portanto, a seqüência $\mathrm{Q}(\mathrm{PO})(\mathrm{ZQ})(\mathrm{PO})$ foi considerada a mais adequada para o branqueamento TCF dessa amostra. A seqüência apresenta boa flexibilidade sob o ponto de vista de teto de alvura, podendo-se ajustá-lo em função da dosagem de peróxido de hidrogênio na última etapa (PO). A flexibilidade no teto de alvura torna essa sequiência atrativa, pois ela é flexível a variações da alvura inicial da fibra secundária, fato extremamente comum.

A necessidade de uma segunda etapa de quelação pode ser questionável em alguns casos. No caso dessa amostra, o perfil de metais da polpa mediante a sequiência $\mathrm{Q}(\mathrm{PO}) \mathrm{Q}(\mathrm{PO})$ está apresentado na Tabela 7. Verifica-se que uma fração significante dos metais de transição, especialmente do ferro, ainda persiste na polpa após o primeiro e o segundo estágio de quelação da sequiência. Entretanto, o teor de manganês, após o segundo estágio de quelação, foi suficientemente baixo (0.97 ppm). Isso permite uma ação efetiva do peróxido na segunda etapa de peroxidação. Após o primeiro estágio de quelação, o teor de manganês na polpa era de 1,88 ppm, um valor ainda muito alto para o branqueamento com peróxido. Portanto, a segunda etapa de quelação é, realmente, necessária para o efetivo branqueamento da amostra com peróxido de hidrogênio.

TABELA 7: Efeito da quelação no perfil de metais da amostra, durante o branqueamento.

\begin{tabular}{l|r|c|c|c|c}
\hline \multirow{2}{*}{ Amostra de Polpa } & \multicolumn{5}{|c}{ Metais, $\mathrm{mg} / \mathrm{kg}$} \\
\cline { 2 - 6 } & $\mathrm{Ca}$ & $\mathrm{Mg}$ & $\mathrm{Fe}$ & $\mathrm{Cu}$ & $\mathrm{Mn}$ \\
\hline Original & 1309 & 178 & 79,6 & 4,31 & 3,28 \\
Após $\mathrm{Q}_{2}$ & 1080 & 107 & 64,3 & 4,03 & 1,88 \\
Após $\mathrm{Q}_{2}(\mathrm{PO})_{15} \mathrm{Q}_{1}$ & 643 & 133 & 36,1 & 2,01 & 0,97 \\
\hline
\end{tabular}

\section{CONCLUSÕES}

Neste estudo foram avaliadas sequiências ECF e TCF para o branqueamento de celulose de fibras secundárias destintadas provenientes de uma mistura de composição conhecida de lixo de escritório (MOW) e produzidas em planta piloto. A polpa foi branqueada ao nível mínimo de alvura de $78 \%$ ISO, sendo que o requerimento de reagentes e as principais propriedades da polpa foram avaliadas. Os resultados desse estudo levaram às seguintes conclusões principais:

- As seqüências mais adequadas para o branqueamento por processos ECF, Z-TCF e TCF são, respectivamente, DEDD, Q(PO)(ZQ)(PO) e Q(PO)Q(PO).

- A presença do ozônio é fundamental no branqueamento TCF das polpas de kappa baixo, especialmente quando altas alvuras são requeridas. 
- Exceto pelos compostos à base de cloro, o ozônio é o único reagente efetivo na remoção de fluorescência de celulose de fibras secundárias, especialmente quando aplicado em dois estágios. O peróxido de hidrogênio aumenta a fluorescência da polpa e o ditionito tem muito pouco efeito.

- Todos os reagentes que aumentam a alvura da fibra secundária decrescem também suas coordenadas de cor $b^{*}$.

- Somente os reagentes à base de cloro removeram, simultaneamente, a fluorescência e a coordenada de cor $b^{*}$ da celulose de fibras secundárias avaliadas.

- $\mathrm{O}$ uso de hidrosulfito (Y) adicionalmente ao $\mathrm{Q}(\mathrm{PO}) \mathrm{Q}(\mathrm{PO})$ não é recomendado para o branqueamento de celulose de fibras secundárias avaliada.

- Uma etapa de remoção de metais Q é absolutamente necessária para o branqueamento de celulose de fibras secundárias por processos TCF. Q(PO)Q(PO), nesse caso, duas etapas são sugeridas.

- Estágios de branqueamento fortemente alcalinos, e realizados em alta temperatura, resultam em alta perda de rendimento durante o branqueamento de celulose de fibras secundárias.

\section{REFERÊNCIAS BIBLIOGRÁFICA}

AIR PRODUCTS AND CHEMICALS, Ronald Charles Naddeo, Augustine Ivanhoe Dalton. Processo de descoramento e alvejamento de polpa compreendendo fibra celulósica secundária. Int. CI ${ }^{4}$ D21C 9/14. BRn. PI 9004623 A. 17 set. 1990; 10 set. 1991a.

AIR PRODUCTS AND CHEMICALS, Augustine Ivanhoe Dalton. "Aperfeiçoamento na deslignificação de fibra contendo lignocelulose”. Int. CI ${ }^{4}$ D21C 9/14. BRn. PI 9004674 A. 19 set. 1990; 10 set. 1991 b.

AIR PRODUCTS AND CHEMICALS, Ronald Charles Naddeo, Konstantinos Hristofas, Vincent Louis Magnotta. Oxygen color stripping in secondary fibers recovery. Int. $\mathrm{CI}^{5} \mathrm{D} 21 \mathrm{C} 5 / 02$. BRn. PI 9201920 A. 21 maio 1992; 5 jan. 1993a.

AIR PRODUCTS AND CHEMICALS, Ronald Charles Naddeo, Konstantinos Hristofas, Vincent Louis Magnotta. Dye removal in oxygen color stripping of secondary fibers. Int. $\mathrm{CI}^{5} \mathrm{D} 21 \mathrm{C}$ 5/02. USn.5,211,809. 21 May 1991; 18 May 1993b.

AIR PRODUCTS AND CHEMICALS, Ronald Charles Naddeo, Konstantinos Hristofas, Vincent Louis Magnotta. Dye stripping by oxygen and peroxide in secondary fiber recovery. Int. $\mathrm{CI}^{5}$ D21C 5/02. USn. 5,324,390. 2 Mar. 1993; 28 June 1994a.

AIR PRODUCTS AND CHEMICALS, Ronald Charles Naddeo, Konstantinos Hristofas, Vincent Louis Magnotta. Dye stripping by oxygen in secondary fiber recovery. Int. $\mathrm{CI}^{5} \mathrm{D} 21 \mathrm{C} 5 / 02$. USn. 5,324,390. 3 Mar. 1993; 26 Jul. 1994b.

AXEGARD, P. Improvement of bleach plant effluent by cutting black on $\mathrm{Cl}_{2}$. Pulp Paper Canada, 90(5): T183-T187, 1989. 
COLODETTE, J.L. Factors affecting hydrogen peroxide stability in the brightening of mechanical and chemimechanical pulps. New York: Syracuse State University, 1986. 273 p. Tese (Doctor of Philosophy) - Syracuse State University, 1986.

COLODETTE, J.L., GOMIDE, J.L., SALLES, D.V.C., et al. Factors affecting kraft pulp bleachability with oxygen derived chemicals. In: NON-CHLORINE BLEACHING CONFERENCE, 1996, Orlando. Anais... Orlando: s.n., 1996, 20p.

D’ALMEIDA, M.L., CAHEN, R. Reciclagem de papel. O Papel, São Paulo, v.52, n.11, p. 131$135,1991$.

JENNINGS, J.P., THOMAS, C.D., MAGNOTTA, V.L. et al. Characterization of a commercial oxygen-bleaching stage in a mill recycling mixed office wastepaper. Tappi Journal, v.79, n.7, p. 119-125, 1996.

MARKHAM, L.D., COURCHENE, C.E. Oxygen bleaching of secondary fiber grades. In: PULPING CONFERENCE, 1988, Atlanta. Anais... Atlanta: Tappi, 1988. v.1, p. 189-196.

NADDEO, R.C., MAGNOTTA, V.L., HRISTOFAS, K. et al. Oxidative methods offer alternative to chlorine bleaching of wasterpper. Pulp and Paper, Atlanta, v.66, n.11, p. 71-81,1992.

PARTHASARATHY, V.R. Elemental chlorine free (ECF) and totally chlorine free (TCF) bleaching of colored broke. Tappi Jounal, Atlanta, v.80, n.7, p. 159-169, 1997.

PATT, R., GEHR, V., MATZKE, W. et al. New approaches in bleaching of recycled fibers. Tappi Journal, Atlanta, v.79, n.12, p. 143-151, 1996.

SINGH, R.P. Bleaching . In: HENMILTON, F., LEOPODO, B. (Eds.). Pulp and paper manufacture. 3.ed. Atlanta: Tappi, 1987. v.3, p.234 - 237.

STUS, W.L. Color stripping of recycled wood-free papers using ozone. Kalamazoo, Michigan: Western Michigan University, 1996. 59p. (A Thesis to requirements for the Senior Design PAPR 473 Course). 